\title{
A IMPORTÂNCIA DO BRINCAR NAS ATIVIDADES FÍSICAS PARA PORTADORES DE NECESSIDADES ESPECIAIS
}

Fernando H. Sousa, Universidade Estadual Paulista Júlio de Mesquita Filho - UNESP, Marília, São Paulo - Brasil

\section{RESUMO}

Este trabalho foi desenvolvido para relatar e discutir os aspectos relacionados à atividade física de indivíduos portadores de necessidades especiais. Teve como objetivo analisar de maneira qualitativa, a partir do contexto do desenvolvimento infantil, a influência do Brincar nas atividades físicas realizadas por portadores de necessidades especiais. Foi realizada revisão bibliográfica em bases de dados disponíveis na internet (Pubmed e Scielo) e publicações em periódicos e em anais de congressos científicos. Como resultado foi verificado que o Brincar na atividade física em indivíduos portadores de necessidades especiais é um instrumento que fornece a experiência necessária ao seu desenvolvimento motor, sensorial, perceptual, cognitivo, afetivo e cultural.

Palavras - Chave: Atividade física; Necessidades especiais; Desenvolvimento infantil.

\section{THE IMPORTANCE OF PLAY IN PHYSICAL ACTIVITY FOR PEOPLE WITH SPECIAL NEEDS}

\begin{abstract}
This work was developed to report and discuss the aspects related to physical activity for individuals with disabilities. Aimed to analyse qualitative way, from the context of child development, the influence of Play in physical activities carried out by people with special needs. Bibliographic review was held in databases available on the Internet (Pubmed and Scielo) and publications in journals and proceedings of scientific congresses. As a result it was verified that the playground in physical activity in individuals with disabilities is an instrument that provides the necessary experience to your motor development, sensory, perceptual, cognitive, affective and cultural.
\end{abstract}

Key-Words: Physical activity; Special needs; Child development 


\section{INTRODUÇÃO}

A criança tem como características principais a alegria, a espontaneidade, o desejo de brincar e interagir-se a todo instante com outras pessoas, sendo que, durante o seu desenvolvimento, é possível a aquisição de um amplo repertório motor.

O desenvolvimento humano é caracterizado por etapas importantes, com características próprias; o desenvolvimento físico ocorre desde o processo embrionário, quando já há presença de estímulos importantes ao seu crescimento. Após nascer, a relação mãe/bebê se fortalece e ocorre a estimulação da criança pelos atos de tocar-lhe, acariciar, amamentar e por estimulação visual. ${ }^{1}$

Desde o início de sua vida, a criança recebe estímulos através do contato com seus brinquedos, o que possibilita o subsídio para o desenvolvimento de habilidades e aquisição de um adequado repertório motor.A educação motora condiciona os aprendizados escolares, a consciência corporal, espacial e temporal, além da coordenação motora; sugere que deva ser estimulada a psicomotricidade precoce, a fim de prevenir futuras complicações no desenvolvimento da criança. ${ }^{2}$

$\mathrm{Na}$ fase de desenvolvimento infantil, de 8 a 10 anos, a criança necessita de estímulos motores e cognitivos; a criança adquiri conceitos através de repetições, da memorização, da imitação e da observação. ${ }^{1}$

O desenvolvimento social da criança se dá pelo convívio social com os pais, amigos, familiares e colegas de escola. A criança constrói capacidades sociais, por meio do 
conjunto de comportamentos dados ao indivíduo em uma relação interpessoal que expressam os sentimentos, atitudes, desejos e opiniões. ${ }^{3}$

Nos ambientes vivenciados pelas crianças, chamados de microssistemas (casa, escola, programas de atividades físicas), há o aprendizado de valores culturais e interações sociais com o meio, além de constituir um cenário propício ao desenvolvimento, que auxiliam na construção da identidade social. O memento da realização de atividade física tem por finalidade de promover de maneira global, os aspectos motores, sociais, e a consciência corporal. $^{4-5}$

O termo brincar origina-se do latim vinculum, que significa união, laço. Sendo assim pode se dizer que o brincar, então, é uma forma de criar e fortalecer vínculos. Ela também afirma que o brincar configura um espaço potencial onde fatos podem ser revividos e elaborados, sendo este um momento privilegiado de atenção integral à criança. ${ }^{6}$

Brinquedo significa tanto o objeto que serve para brincar como o ato de brincar; jogo é a atividade com regras que definem uma disputa "que serve para a criança brincar"; a brincadeira é, "o ato ou efeito de brincar, entreter-se, distrair-se com um brinquedo ou jogo".

O brincar é uma possibilidade de expressão de sentimentos, preferências, receios e hábitos; mediação entre o mundo familiar e situações novas ou ameaçadoras; e elaboração de experiências desconhecidas ou desagradáveis e pode ser visto como um espaço terapêutico que promove continuidade no desenvolvimento. ${ }^{8}$ 
Por sua característica universal, o brincar, identifica-se como uma linguagem comum a todos, pois a comunicação é através das brincadeiras e das relações estabelecidas. A partir da brincadeira a criança torna-se espontânea, desenvolve-se e revela-se de maneira transparente na vida lúdica, brinca por necessidade interior, e prepara-se para a maturidade. A criança não brinca por brincar, sendo que o próprio brinquedo mostra o caminho escolhido por ela, pelo qual devemos aproveitar e trabalhar. ${ }^{9}$

Um dos aspectos mais importantes do brincar é a dramatização, pois, por meio dela, a criança aprende sobre a vida real. O brincar faz parte da vida, tanto que o jogo é vida que se a pessoa não quer saber de jogar, ela não sabe viver. ${ }^{7}$

\section{MATERIAL E MÉTODO}

Existem diversos caminhos para a reflexão sobre a produção do conhecimento de determinada área, e nesta pesquisa a optou-se pela revisão bibliográfica.

Em relação ao tipo de fonte de pesquisa, foram analisados artigos científicos publicados em bases de dados disponíveis na internet através da Biblioteca Virtual Scielo e da Biblioteca Virtual Médica dos EUA, PubMed, além de publicações em periódicos e em anais de congressos científicos.

A análise dos artigos foi realizada de maneira qualitativa, ou seja, foram interpretados os sentidos das idéias centrais dos artigos. 
Esta revisão bibliográfica foi baseada na leitura e interpretação qualitativa dos resultados encontrados no banco de dados da Biblioteca Virtual Médica dos EUA, Pubmed e da Bibiloteca Virtual Scielo, utilizando para a busca as palavras-chave criança, atividade física, brincar e atividade lúdica, além de publicações em periódicos e anais de congressos científicos.

\section{RESULTADOS}

Em relação à sociedade em que estão inseridas as crianças e seus comportamentos discute a criança com necessidades especiais nos dias atuais, vendo a necessidade de repensar o convívio em sociedade, a fim de possibilitar a expressão das necessidades de movimento das crianças em um clima de harmonia. ${ }^{10}$

O jogo é uma necessidade infantil, tem uma finalidade educacional porque começa como exercício funcional. A criança que joga, torna-se um adulto preparado. ${ }^{11}$

São seis os princípios do brincar: 1) é autêntico, por ser "um complexo conjunto de comportamentos caracterizado por diversão e espontaneidade"; 2) "é sensorial, neuromuscular, mental"; 3) "envolve repetição, exploração, experiência e imitação de alguém que esteja por perto"; 4) "tem limite e tempo, que são determinados pela criança e/ou adulto, na comparação que faz da realidade/fantasia com a realidade"; 5) permite “integrar o mundo interno ao mundo externo" e 6) "segue uma seqüência, uma progressão de desenvolvimento". 7 
As pessoas com deficiência física têm certa especificidade nas suas características e, portanto, necessidades de mediação social, de comunicação, de socialização, de atividades culturais, entre outras, que são universais. Mas universal é a brincadeira, "que é própria da saúde, pois facilita o crescimento, conduz aos relacionamentos grupais e é uma forma de comunicação. ${ }^{7}$

\section{DISCUSSÃO}

A funcionalidade adquirida através da brincadeira na atividade física se observa na facilitação de postura, controle muscular para propiciar aquisição das atividades de vida diária, seleção de estímulos motores, sensoriais e cognitivos.

Desta forma, o jogo e o brincar se tornam uma totalidade. Toda brincadeira é uma diversão, que significa "mudança de direção para uma e outra parte". Assim, o brincar é uma mudança e toda mudança é uma experiência que faz parte do jogo e da vida.

O brincar é organizado, combina movimentos complexos, apreende as situações do ambiente e se adapta a elas. Pelas brincadeiras, as crianças portadoras de necessidades especiais exploram o seu próprio corpo e o seu ambiente, desenvolvendo as sensações exteroceptivas, proprioceptivas e vestibulares.

O brincar na atividade física para crianças com necessidades especiais é um instrumento que fornece a experiência necessária ao seu desenvolvimento motor, sensorial, perceptual, cognitivo, afetivo e cultural. 
A brincadeira constitui um desafio e, ao mesmo tempo, possibilita atingir a meta desejada com seu próprio esforço. Assim, a criança com necessidades especiais realiza uma troca com seu meio e favorece seu desenvolvimento motor, sensorial, cognitivo, afetivo e social.

Existe uma diferença entre estimular brincando e brincar para estimular. No primeiro caso, partindo de uma determinada necessidade da criança, tentamos despertar o seu interesse com um brinquedo ou uma brincadeira e, no segundo, com uma visão holística, suprimos suas necessidades, colocando o seu interesse em primeiro lugar.

Assim, pode-se concluir que o brincar sugere uma liberdade de criar situações e de realizar outro movimento que não o esperado, e o papel da atividade física, é criar situações em atividades funcionais, que estimulem a criança com necessidades especiais de forma global. A própria brincadeira, por ser simples, além de ainda estar na memória da maioria das pessoas, facilita a comunicação do profissional com seu paciente, e vice-versa, e será o agente catalisador do processo de desenvolvimento.

\section{REFERENCIAS}

${ }^{1}$ BLADES, M; COWIE, H; SMITH, P. K. Compreender o desenvolvimento da criança. Lisboa: Instituto Piaget, 2001. 631 p.

${ }^{2}$ LE BOULCH, J. O desenvolvimento psicomotor: do nascimento aos 6 anos. Porto Alegre: Artes Médicas, 1982. 220 p. 
${ }^{3}$ CABALlO, VE.; MARINHO, ML. Comportamento anti-social infantil e seu impacto para a competência social. Psicologia, Saúde e Doenças, Lisboa, v. 3, n. 2, p. 141-147, 2002.

${ }^{4}$ BRONFENBRENNER, U. A ecologia do desenvolvimento humano: experimentos naturais e planejados. Porto Alegre: Artes Médicas, 1996. 267 p.

${ }^{5}$ MERINO, E.; TENROLler, C. A. Métodos e planos para o ensino dos esportes. Canoas: Editora ULBRA, 2006. 204 p.

${ }^{6}$ JUNQUEIRA, M. F. P. S. A mãe, seu filho hospitalizado e o brincar: um relato de experiência. Estudos de Psicologia, v.8, n. 3, p. 193-197, 2003.

${ }^{7}$ LORENZINI, M. V. Brincando a brincadeira com a criança deficiente. São Paulo: Editora Manole, 2002.

${ }^{8}$ MITRE, R. M. A.; GOMES, R. A Promoção do brincar no contexto da hospitalização infantil como ação de saúde.2003. p.174-154.

${ }^{9}$ GESELL, A. A criança de 5 a 10 anos. 3. ed. São Paulo: Martins Fontes, 1998.

${ }^{10}$ NETO, C. A. F. Motricidade e jogo na infância. Rio de Janeiro: Sprint, 2001.

${ }^{11}$ MACEDO, L. Jogos infantis: aspectos afetivos e cognitivos. In: SIMPÓSIO UNESP DE PSICOLOGIA E EDUCAÇÃO. COMPORTAMENTO, COGNIÇÃO E AFETIVIDADE: Conexões: revista da Faculdade de Educação Física da UNICAMP, Campinas, v. 9, n. 1, p. 157-165, jan./abr. 2011. ISBN: 1983-9030 
TENDÊNCIAS ATUAIS EM PSICOLOGIA E EDUCAÇÃO, 1. Marilia, 1991. Anais.... Marília: Universidade Estadual Paulista “Júlio de Mesquita Filho”, 1991. 